\title{
Editorial
}

\section{Landsat-8 Sensor Characterization and Calibration}

\section{Brian Markham 1,†, James Storey ${ }^{2, \dagger}$ and Ron Morfitt ${ }^{3, \dagger}$}

1 NASA/GSFC, Code 618, Greenbelt, MD 20771, USA; E-Mail: brian.1.markham@nasa.gov; Tel.: +1-301-614-6608

2 Stinger Ghaffarian Technologies (SGT), Technical Support Services Contractor to USGS EROS, NASA/GSFC Mail Code 618, Greenbelt, MD 20771, USA; E-Mail: james.c.storey@nasa.gov; Tel.: +1-301-614-6683

3 USGS Earth Resources Observation and Science (EROS) Center, 47914 252nd Street, Sioux Falls, SD 57198, USA; E-Mail: rmorfitt@usgs.gov; Tel.: +1-605-594-2688

$\dagger$ These authors contributed equally to this work.

Academic Editor: Prasad S. Thenkabail

Received: 15 February 2015 / Accepted: 17 February 2015 / Published: 25 February 2015

Landsat-8 was launched on 11 February 2013 with two new Earth Imaging sensors to provide a continued data record with the previous Landsats. For Landsat-8, pushbroom technology was adopted, and the reflective bands and thermal bands were split into two instruments. The Operational Land Imager (OLI) is the reflective band sensor and the Thermal Infrared Sensor (TIRS), the thermal. In addition to these fundamental changes, bands were added, spectral bandpasses were refined, dynamic range and data quantization were improved, and numerous other enhancements were implemented. As in previous Landsat missions, the National Aeronautics and Space Administration (NASA) and United States Geological Survey (USGS) cooperated in the development, launch and operation of the Landsat8 mission. One key aspect of this cooperation was in the characterization and calibration of the instruments and their data. This Special Issue documents the efforts of the joint USGS and NASA calibration team and affiliates to characterize the new sensors and their data for the benefit of the scientific and application users of the Landsat archive. A key scientific use of Landsat data is to assess changes in the land-use and land cover of the Earth's surface over the now 43-year record. In order to perform these analyses and avoid confusing sensor changes with Earth surface changes, a solid understanding of the sensors' performance, consistent geolocation and radiometry are essential. Particularly with the significant changes in the Landsat- 8 sensors relative to previous Landsat missions, this characterization becomes all the more important. 
The content of the special issue is approximately evenly split between the two sensors and similar material is covered for each sensor, though not necessarily parsed the same way into papers. The instruments' design and pre-launch characterization are covered in one paper for each instrument (Knight and Kvaran [1] for OLI; Reuter et al. [2], for TIRS). Additional details on the TIRS pre-launch radiometric characterization are included in Montanaro et al. [3] for TIRS, including the spectral response characterization. For OLI the spectral response characterization is separately discussed in a dedicated paper (Barsi et al. [4]). Spatial characterization is included in the OLI design paper, but broken out separately for TIRS in Wenny et al. [5], and this paper includes on-orbit results as well. A particular aspect of the spatial performance of the TIRS instrument that has been the focus of much attention, stray light, is discussed in detail in Montanaro et al. [6].

Geometric characterization of the instrument and data both prior to launch and on-orbit are covered in Storey et al. [7] for OLI and Storey et al. [8] for TIRS. Radiometric performance of the two sensors is covered in a number of papers. Details of the on-orbit performance in terms of noise, detector operability, linearity, dynamic range and similar topics is covered in Morfitt et al. [9] for OLI and Montanaro et al. [10] for TIRS. Absolute calibration and stability using the on-board calibration devices is covered in the same paper [10] for TIRS, but in detail in a separate paper for OLI (Markham et al., [11]). Analysis of an alternate way to perform detector-to-detector relative radiometric calibration to reduce striping and banding artifacts in imagery is discussed in two papers: Pesta et al. [12] which specifically examines OLI and Gerace et al. [13], which examines strategies from a more theoretical standpoint using simulations. Validation of the OLI and TIRS radiometric calibrations by using surface measurements, also known as vicarious calibration and by comparison to other instruments, e.g., the Landsat-7 ETM+ is covered in five papers. Czapla-Myers et al. [14] reports on the vicarious calibration of OLI and Mishra et al., [15] and Flood [16] examine OLI's cross calibration with Landsat-7 ETM+. Barsi et al. [17] and Cook et al. [18] focus on the vicarious calibration of the TIRS instrument.

\section{Acknowledgments}

We would like to thank the authors of this Special Issue for their contributions and timely responses to reviewers, the reviewers for their timely and quality reviews and the Remote Sensing editorial team for their support.

\section{Author Contributions}

All authors contributed equally to this work.

\section{Conflicts of Interest}

The authors declare no conflict of interest.

\section{References and Notes}

1. Knight, E.; Kvaran, G. Landsat-8 Operational Land Imager design, characterization and performance. Remote Sens. 2014, 6, 10286-10305; doi:10.3390/rs61110286. 
2. Reuter, D.; Richardson, C.; Pellerano, F.; Irons, J.; Allen, R.; Anderson, M.; Jhabvala, M.; Lunsford, A.; Montanaro, M.; Smith, R.; Tesfaye, Z.; Thome, K. The Thermal Infrared Sensor (TIRS) on Landsat 8: Design overview and pre-launch characterization. Remote Sens. 2015, 7, 1135-1153; doi:10.3390/rs70101135.

3. Montanaro, M.; Lunsford, A.; Tesfaye, Z.; Wenny, B.; Reuter, D. Radiometric calibration methodology of the Landsat 8 Thermal Infrared Sensor. Remote Sens. 2014, 6, 8803-8821; doi:10.3390/rs6098803.

4. Barsi, J.; Lee, K.; Kvaran, G.; Markham, B.; Pedelty, J. The spectral response of the Landsat-8 Operational Land Imager. Remote Sens. 2014, 6, 10232-10251; doi:10.3390/rs61010232.

5. Wenny, B.; Helder, D.; Hong, J.; Leigh, L.; Thome, K.; Reuter, D. Pre- and post-launch spatial quality of the Landsat 8 Thermal Infrared Sensor. Remote Sens. 2015, 7, 1962-1980; doi:10.3390/rs70201962.

6. Montanaro, M.; Gerace, A.; Lunsford, A.; Reuter, D. Stray light artifacts in imagery from the Landsat 8 Thermal Infrared Sensor. Remote Sens. 2014, 6, 10435-10456; doi:10.3390/rs61110435.

7. Storey, J.; Choate, M.; Lee, K. Landsat 8 Operational Land Imager on-orbit geometric calibration and performance. Remote Sens. 2014, 6, 11127-11152; doi:10.3390/rs61111127.

8. Storey, J.; Choate, M.; Moe, D. Landsat 8 Thermal Infrared Sensor geometric characterization and calibration. Remote Sens. 2014, 6, 11153-11181; doi:10.3390/rs61111153.

9. Morfitt, R.; Barsi, J.; Levy, R.; Markham, B.; Micijevic, E.; Ong, L.; Scaramuzza, P.; Vanderwerff, K. OLI radiometric performance on-orbit. Remote Sens. 2015, 7, 2208-2237; doi:10.3390/rs70202208.

10. Montanaro, M.; Levy, R.; Markham, B. On-Orbit Radiometric Performance of the Landsat 8 Thermal Infrared Sensor. Remote Sens. 2014, 6, 11753-11769; doi:10.3390/rs61211753.

11. Markham, B.; Barsi, J.; Kvaran, G.; Ong, L.; Kaita, E.; Biggar, S.; Czapla-Myers, J.; Mishra, N.; Helder, D. Landsat-8 operational land imager radiometric calibration and stability. Remote Sens. 2014, 6, 12275-12308; doi:10.3390/rs61212275.

12. Pesta, F.; Bhatta, S.; Helder, D.; Mishra, N. Radiometric non-uniformity characterization and correction of Landsat 8 OLI using earth imagery-based techniques. Remote Sens. 2015, 7, 430-446; doi:10.3390/rs70100430.

13. Gerace, A.; Schott, J.; Gartley, M.; Montanaro, M. An analysis of the side slither on-orbit calibration technique using the DIRSIG Model. Remote Sens. 2014, 6, 10523-10545; doi:10.3390/rs61110523.

14. Czapla-Myers, J.; McCorkel, J.; Anderson, N.; Thome, K.; Biggar, S.; Helder, D.; Aaron, D.; Leigh, L.; Mishra, N. The ground-based absolute radiometric calibration of Landsat 8 OLI. Remote Sens. 2015, 7, 600-626; doi:10.3390/rs70100600.

15. Mishra, N.; Haque, M.; Leigh, L.; Aaron, D.; Helder, D.; Markham, B. Radiometric cross calibration of Landsat 8 Operational Land Imager (OLI) and Landsat 7 Enhanced Thematic Mapper Plus (ETM+). Remote Sens. 2014, 6, 12619-12638; doi:10.3390/rs61212619.

16. Flood, N. Continuity of reflectance data between Landsat-7 ETM+ and Landsat-8 OLI, for both Top-of-Atmosphere and surface reflectance: A study in the Australian landscape. Remote Sens. 2014, 6, 7952-7970; doi:10.3390/rs6097952. 
17. Barsi, J.; Schott, J.; Hook, S.; Raqueno, N.; Markham, B.; Radocinski, R. Landsat-8 Thermal Infrared Sensor (TIRS) vicarious radiometric calibration. Remote Sens. 2014, 6, 11607-11626; doi:10.3390/rs61111607.

18. Cook, M.; Schott, J.; Mandel, J.; Raqueno, N. Development of an operational calibration methodology for the Landsat thermal data archive and initial testing of the atmospheric compensation component of a Land Surface Temperature (LST) Product from the archive. Remote Sens. 2014, 6, 11244-11266; doi:10.3390/rs61111244.

(C) 2015 by the authors; licensee MDPI, Basel, Switzerland. This article is an open access article distributed under the terms and conditions of the Creative Commons Attribution license (http://creativecommons.org/licenses/by/4.0/). 